\title{
Expression of Insoluble Influenza Neuraminidase Type 1 (NA1) Protein in Tobacco
}

\author{
Teen Lee Pua ${ }^{1}$, Hwei San Loh ${ }^{1 *}$, Festo Massawe ${ }^{1}$, Chon Seng Tan ${ }^{2}$, Abdul Rahman Omar ${ }^{3}$ \\ ${ }^{1}$ School of Biosciences, Faculty of Science, The University of Nottingham Malaysia Campus, Semenyih, Selangor, Malaysia \\ ${ }^{2}$ Strategic Resource Research Center, Malaysian Agricultural Research and Development Institute, Selangor, Malaysia. \\ ${ }^{3}$ Institute of Bioscience, Universiti Putra Malaysia, Selangor, Malaysia.
}

\begin{abstract}
The avian influenza virus, particularly H5N1 strain, is highly virulent to poultry and mankind. Several expression systems, like yeast, baculovirus and mammalian cells, have been adopted to produce vaccine candidate for this lethal disease. The present research aimed at developing a recombinant vaccine candidate, neuraminidase type 1 (NA1), for the Malaysia isolate of H5N1 in Nicotiana benthamiana. The $N A 1$ gene was fused directly in-frame in cowpea mosaic virus (CPMV)-based pEAQ$H T$ vector with $\mathrm{C}$-terminal polyhistidine-tag incorporated to ease the subsequent purification step. The expression of the $N A 1$ gene in tobacco was confirmed at RNA and protein levels at 6 days postinfiltration (Dpi). From the insoluble fraction of the protein, a recombinant glycosylated NA1 protein with a molecular weight of $\sim 56 \mathrm{kDa}$ was immunogenically detected by a specific anti-NA polyclonal antibody. We report for the first time the insolubility of the plant-made NA1 protein where a native sequence was used for its expression. This study signifies the necessity of the use of optimised sequences for expression work and provides great opportunity for the exploration of plantmanufactured NA1 protein as vaccine candidate.
\end{abstract}

Keywords: Avian Influenza, H5N1, Neuraminidase, Plant virus-based expression system, Recombinant protein

\section{INTRODUCTION}

Highly pathogenic avian influenza (AI), $\mathrm{H} 5 \mathrm{N1}$, in poultry has fuelled intense media coverage and health concerns due to the severe outbreaks in Asia, Africa and Europe. This deadly pandemic is still showing a great potential of spreading. The development of vaccine candidates for AI is utmost crucial and could serve as the best strategy for managing the disease. Two of the currently licensed vaccines against influenza are conventional inactivated virus vaccine (CIV) and live-attenuated vaccine (LAV) with an objective of complete infection inhibition. These vaccines are dominated by the anti-haemagglutinin (HA) immune response, and hence, the effectiveness is restricted to virus strains with closely matched HA. They are susceptible to protect failures in cases where

*Corresponding author: H.S. Loh

School of Biosciences, Faculty of Science, The University of Nottingham Malaysia Campus, Jalan Broga 43500 Semenyih, Selangor, Malaysia.

Tel: +060389248215

Fax: +060389248018

Email: Sandy.Loh@nottingham.edu.my antigenic drift or shift occurred on HA [1]. Therefore, antiviral drugs like Tamiflu ${ }^{\circledR}$ (oseltamivir) and Relenza ${ }^{\circledR}$ (zanamivir) have been used widely to treat patients with early infection [2]. These drugs inhibit neuraminidase (NA) main function, which is to facilitate the release of the progeny virions from infected cells. By this, the virus spread is restricted and disease onset is suppressed. However, virus strain with NAinhibitor resistance has been observed and identified [3]. Therefore, it seems the vaccine candidate targeting NA is still handy in this case.

For a better protection against heterovariant influenza viral infection, vaccines containing equal levels of immunogenic $\mathrm{HA}$ and NA antigens are required. Inclusion of NA offers a better prospect in this case due to its slower rate of antigenic evolution [1]. Instead of infection inhibition, NA presents an alternative strategy called infection-permissive immunization. Previous studies have described that CIV and LAV supplemented with purified NA protein or recombinant NA protein yielded equivalent level of both anti-HA and anti-NA antibody titres $[4,5]$. The viral replication was significantly 
reduced in response to heterotypic virus challenges. Recombinant NA protein is favourable due to its production simplicity as compared to the laborious purification process of native NA protein from influenza virion. Plant system has been used to produce several recombinant proteins due to its great advantages over other competing systems. Plant systems offer opportunities to produce vaccines at low cost, it is easy to scale-up, and has low risk of contamination with animal pathogens. Plantbased vaccine also provides a new approach of oral delivery [6], provided these immunogenic peptides are expressed in an edible crop plant, such as corn [7]. Hence, downstream purification cost or injection-related hazard can be eliminated. In this study, we aimed to engineer a recombinant NA1 protein from a Malaysian isolate and express it in tobacco using a viral vector. We describe the construction of the recombinant vector and the expression of NA1 gene at both RNA and protein levels.

\section{MATERIALS AND METHODS}

\section{NA1 Sequence and Plant Viral Vectors}

The NA1 gene of a local isolate Avian Influenza (AI) virus strain A/chicken/Malaysia/5744/2004(H5N1) was kindly supplied by Professor Abdul Rahman Omar from the Institute of Bioscience, Universiti Putra Malaysia, Malaysia. Native $N A 1$ sequence was used in the construction of recombinant vector. CPMV-based plant viral expression vectors, pEAQ-HT and pEAQ-HTGFP were a kind gift from Professor George Lomonossoff (John Innes Centre, UK).

\section{Construction of Recombinant Vector and Its Characterisation}

Full-length of the neuraminidase type 1 (NA1)(450 amino acids) was used for PCR-based cloning. A set of primers incorporated with restriction sites, namely $A g e \mathrm{I}$ (Forward NeuF-AgeI: GCGACCGGTATGAATCCAAATAAGAAGA

TA) and $S m a \mathrm{I}$ (Reverse NeuR-SmaI: GTCCCCGGGCTTGTCAATGGTGAATGGC) was used for PCR amplification. PCR reaction mixture was prepared by adding $1 \mathrm{X}$ of PCR buffer $\mathrm{S}\left(160 \mathrm{mM}\left(\mathrm{NH}_{4}\right)_{2} \mathrm{SO}_{4}, 500 \mathrm{mM}\right.$ Tris- $\mathrm{HCl}$, $17.5 \mathrm{mM} \mathrm{MgCl} 2$ and $0.1 \%$ Triton X-100), 0.4 $\mathrm{mM}$ of dNTP, $0.5 \mu \mathrm{M}$ of each primer, $20 \mathrm{ng}$ template, $1 \mathrm{U}$ of Taq polymerase and made up to $20 \mu \mathrm{l}$ with sterile deionised water. The tubes were heated at $94{ }^{\circ} \mathrm{C}$ for $4 \mathrm{~min}$ and then subjected to twenty five amplification cycles with
$45 \mathrm{sec}$ at $94{ }^{\circ} \mathrm{C}$ for denaturation, $45 \mathrm{sec}$ at $50{ }^{\circ} \mathrm{C}$ for annealing and $1 \mathrm{~min}$ at $72{ }^{\circ} \mathrm{C}$ for extension. Another $5 \mathrm{~min}$ at $72{ }^{\circ} \mathrm{C}$ was added as the final extension step. The PCR products were then electrophoresed at 80 Volt for $40 \mathrm{~min}$ in $0.8 \%$ $(\mathrm{w} / \mathrm{v})$ of agarose gel. The PCR products were purified using MEGAquick-spin TM PCR and Agarose gel DNA extraction system (Intron Biotechnology, Korea) according to manufacturer's instructions. For ligation purpose, the NA1 gene and pEAQ-HT vector were digested by the same restriction enzymes (RE), AgeI and SmaI, to form sticky ends at both cutting sides. The resulting recombinant construct was named as $\mathrm{pEAQ}-H T:: \mathrm{NA} 1$ (Figure 1) and verified by RE digestion. AgeI was used to linearize the recombinant vector. Reaction mixture was prepared by adding $1 \mathrm{X}$ of buffer V2 buffer $\left(10 \mathrm{mM}\right.$ Tris- $\mathrm{HCl} \mathrm{pH} 7.5$ at $30{ }^{\circ} \mathrm{C}, 10$ $\mathrm{mM} \mathrm{MgCl}, 50 \mathrm{mM} \mathrm{NaCl}$ and $0.1 \mathrm{mg} / \mathrm{ml} \mathrm{BSA}$ ), 2 $\mathrm{U}$ of $A g e \mathrm{I}$ (Vivantis, Malaysia), $100 \mathrm{ng}$ of pEAQ$H T:$ NA1 plasmid and made up to $20 \mu \mathrm{l}$ with molecular grade distilled water. AgeI and XhoI were used to release the $N A 1$ gene from the pEAQ-HT vector. Reaction mixture was prepared by adding $1 \mathrm{X}$ of $\mathrm{V} 2$ buffer, $2 \mathrm{U}$ of AgeI (Vivantis, Malaysia), $2 \mathrm{U}$ of XhoI (Promega, USA) and 200 ng of pEAQ-HT::NA1 vector and made up to $20 \mu \mathrm{l}$ with molecular grade distilled water. The reaction mixtures were incubated at $37{ }^{\circ} \mathrm{C}$ for $2 \mathrm{~h}$. After that, the digested product was electrophoresed in a $1.0 \%(\mathrm{w} / \mathrm{v})$ agarose gel. The plasmids were subsequently sent for nucleotide sequencing (Macrogen Inc., Korea).

\section{Agroinfiltration Procedure}

Empty pEAQ-HT, recombinant pEAQ$H T:: N A 1$ and pEAQ-HT-GFP were transformed into $A$. tumefaciens LBA4404 using electroporation method. The resultant transformants were thereafter named as Ag/pEAQ-HT, Ag/pEAQ-HT::NA1 and $\mathrm{Ag} / \mathrm{pEAQ}-H T$-GFP. The cultures were grown to stable phase in Luria-Bertani medium supplemented with $50 \mu \mathrm{g} / \mathrm{ml}$ rifampicin and kanamycin at $28{ }^{\circ} \mathrm{C}$ in shaking condition of 200 $\mathrm{rpm}$. The cells were collected by centrifugation at 6,000 rpm for $10 \mathrm{~min}$ at $4{ }^{\circ} \mathrm{C}$ and resuspended in infiltration buffer $(10 \quad \mathrm{mM} \quad 2-(\mathrm{N}$ morpholino)ethanesulphonic acid (MES), $\mathrm{pH}$ $5.5,10 \mathrm{mM} \mathrm{MgCl} 2,0.1 \mathrm{mM}$ acetosyringone) to an OD600 of 0.3-0.4. After $2 \mathrm{~h}$ of incubation period at room temperature, the suspensions were infiltrated into fully expanded $N$. benthamiana leaves using a syringe without a needle. After infiltration, the plant was further grown under 
greenhouse conditions. Physical appearance of the infiltrated leaves were observed and recorded.

\section{mRNA Assessment of pEAQ::NA1 Infiltrated Plant Samples}

Leaf samples from both pEAQ-HT::NA1infiltrated and mock-infiltrated plants were harvested on six days post-infiltration (Dpi) for total RNA extraction procedure by using TRIzol $^{\circledR}$ reagent (Invitrogen, USA) following manufacturer's protocol. Reverse transcription (RT) was conducted on the RNAs extracted by using Viva 2-steps RT-PCR kit (Vivantis, Malaysia). First-strand cDNA synthesis reaction mixture was prepared by adding $2 \mu \mathrm{g}$ of total RNA, $2 \mu \mathrm{M}$ gene-specific primer (NeuR-SmaI),
$0.5 \mathrm{mM}$ dNTP mix and made up to $10 \mu \mathrm{l}$ with DEPC-treated water. The mixture was incubated at $65{ }^{\circ} \mathrm{C}$ for $5 \mathrm{~min}$ and then placed on ice for 2 min. A $10 \mu \mathrm{l}$ mixture of 1 X RT buffer $(500 \mathrm{mM}$ Tris- $\mathrm{HCl}\left(\mathrm{pH} 8.3\right.$ at $\left.25{ }^{\circ} \mathrm{C}\right), 750 \mathrm{mM} \mathrm{KCl}, 30$ $\mathrm{mM} \mathrm{MgCl}_{2}$ and $100 \mathrm{mM} \mathrm{DTT}$ ) and $100 \mathrm{U} \mathrm{M}$ MuLV Reverse Transcriptase was added to each individual tube. The mixture was incubated at 42 ${ }^{\circ} \mathrm{C}$ for $60 \mathrm{~min}$. Then, the reaction was terminated at $85{ }^{\circ} \mathrm{C}$ for $5 \mathrm{~min}$ and chilled on ice. PCR reaction mixture and its program were similar to previous section as described. RNA extracted was also subjected to PCR without first strand cDNA synthesis as a negative control for tracking of DNA contamination. The PCR products $(20 \mu \mathrm{l})$ were then electrophoresed at 80 Volt for $40 \mathrm{~min}$ in $1.0 \%(\mathrm{w} / \mathrm{v})$ agarose gel.

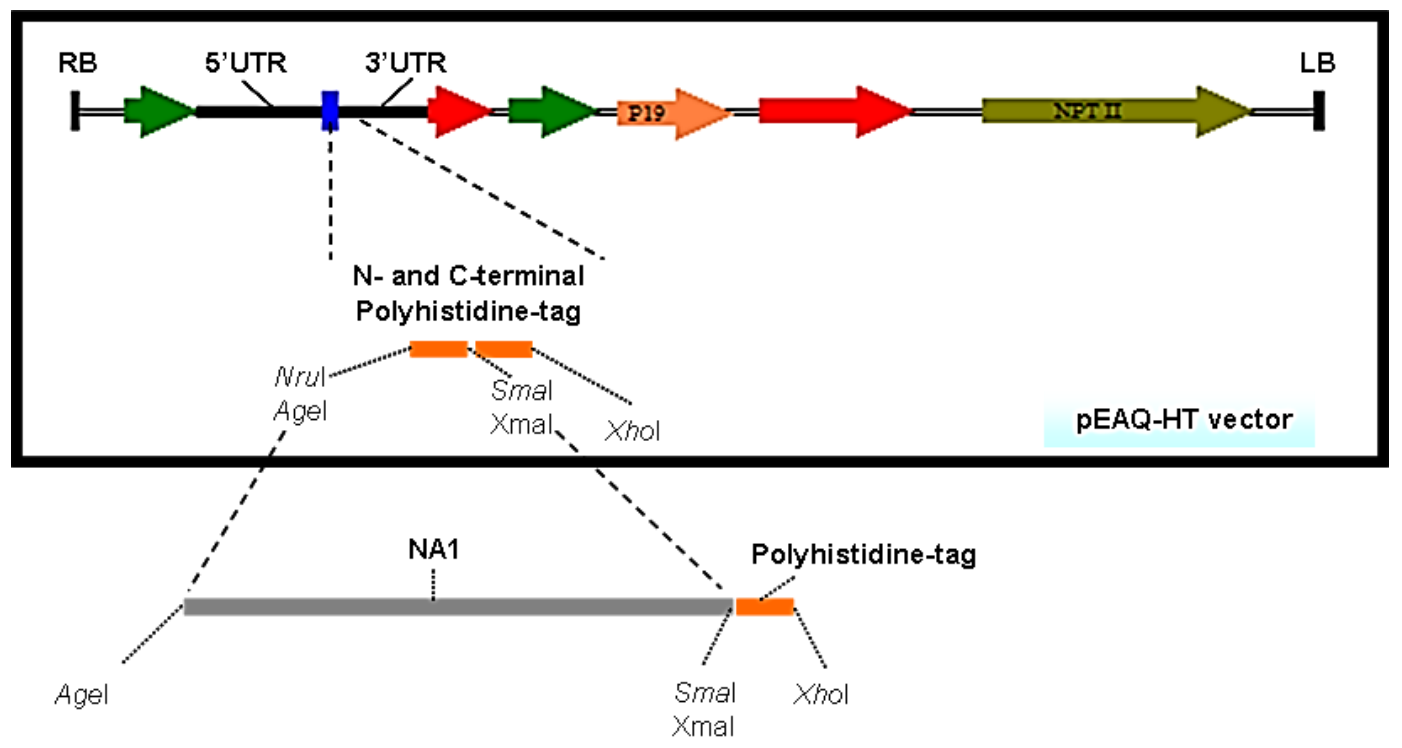

Figure 1. Schematic diagram of pEAQ-HT vector and insertion position of NA1 gene in between AgeI and SmaI sites. (Adopted from [16])

\section{Protein Extraction and SDS-PAGE Electrophoresis}

Proteins were extracted from the Ag/pEAQHT-GFP infiltrated leaves after 3, 6, 9 and 12 Dpi and Ag/pEAQ-HT::NA1 infiltrated leaves after 6 Dpi. Total soluble proteins were extracted according to protocol as described by [8]. Inoculated leaf tissues were frozen in liquid nitrogen and ground to powder using mortar and pestle. Then, the samples were suspended in 2 volumes of soluble protein buffer $(50 \mathrm{mM}$ Tris$\mathrm{HCl} \mathrm{pH} 7.25,150 \mathrm{mM} \mathrm{NaCl}, 0.1 \%$ (v/v) Triton $\mathrm{X}-100,2 \mathrm{mM}$ DTT and 1/100 protease inhibitor cocktail) and centrifuged at $13,000 \mathrm{rpm}$ for 10 min at $4{ }^{\circ} \mathrm{C}$. Supernatants were collected and stored at $4{ }^{\circ} \mathrm{C}$. The pellets of $\mathrm{Ag} / \mathrm{pEAQ}$ -
$H T:$ NA1-infiltrated samples were kept for insoluble proteins extraction.

One millilitre of pre-cooled methanol (with $1 / 100$ protease inhibitor cocktail) was added into each tube. The tubes were vortexed for $30 \mathrm{sec}$, incubated at $-20^{\circ} \mathrm{C}$ for $5 \mathrm{~min}$ and centrifuged for $5 \mathrm{~min}$ at $13,000 \mathrm{rpm}$ at $4^{\circ} \mathrm{C}$. The supernatant was removed with a pipettor and the washing steps were repeated once for methanol and once for acetone. The pellets were brief-dried at room temperature and re-suspended in 1 volume of insoluble protein buffer ( $7 \mathrm{M}$ urea, $2 \mathrm{M}$ thiourea, $40 \mathrm{mM}$ Tris $\mathrm{HCl} \mathrm{pH} \mathrm{7.5,10} \mathrm{mM} \mathrm{DTT} \mathrm{and} \mathrm{1/100}$ protease inhibitor cocktail). The tubes were incubated at $23{ }^{\circ} \mathrm{C}$ for $15 \mathrm{~min}$ under gentle agitation. Then, the samples were centrifuged at $13,000 \mathrm{rpm}$ for $30 \mathrm{~min}$ at $18{ }^{\circ} \mathrm{C}$ and supernatants 
were collected. The proteins extracted were then electrophoresed at 120 Volt for $90 \mathrm{~min}$ in $12 \%$ SDS-PAGE gel.

\section{Protein Purification by Immobilized Metal Affinity Chromatography (IMAC) Resin}

Profinity Ni-charged IMAC resin (BioRad, USA) was suspended thoroughly and $200 \mu \mathrm{l}$ was transferred to Micro Bio-spin column ${ }^{\mathrm{TM}}$ (BioRad, USA). Storage solution was removed by centrifugation $(1,000 \mathrm{rpm})$ for $10 \mathrm{sec}$ and the column was washed by 5 volumes of distilled water. The resin was pre-equilibrated by 5 volumes of binding buffer $\left(50 \mathrm{mM} \mathrm{NaH} \mathrm{PO}_{4}\right.$, $300 \mathrm{mM} \mathrm{NaCl}, 5 \mathrm{mM}$ imidazole and $8 \mathrm{M}$ urea, $\mathrm{pH}$ 8.0) prior to adding $500 \mu \mathrm{l}$ of $\mathrm{Ag} / \mathrm{pEAQ}$ $H T::$ NA1 infiltrated insoluble protein sample. The sample and resin were mixed by pipetting for 5 times. The unbound protein was removed by centrifugation and the column was washed by 5 volumes of washing buffer $\left(50 \mathrm{mM} \mathrm{NaH} \mathrm{PO}_{4}\right.$, $300 \mathrm{mM} \mathrm{NaCl}, 20 \mathrm{mM}$ imidazole and $8 \mathrm{M}$ urea, $\mathrm{pH}$ 8.0). The column was transferred into a new microcentrifuge tube and protein was eluted by $150 \mu \mathrm{l}$ of elution buffer $\left(50 \mathrm{mM} \mathrm{NaH} \mathrm{PO}_{4}, 300\right.$ $\mathrm{mM} \mathrm{NaCl}, 250 \mathrm{mM}$ imidazole and $8 \mathrm{M}$ urea, $\mathrm{pH}$ 8.0).

\section{Western Blotting Analysis}

Western blotting analysis was carried out on total crude protein extracts and IMAC-purified protein extracts. The extracts separated on $12 \%$ SDS-PAGE gel were then transferred onto nitrocellulose membrane (Invitrogen, USA). Primary rabbit polyclonal antibodies against GFP (Abcam, UK) (1:10,000 dilution), primary rabbit polyclonal $\operatorname{IgG}$ antibody rose against avian influenza $A$ neuraminidase (Abcam, UK) (1:10,000 dilution) and horseradish peroxidaseconjugated anti-rabbit $\operatorname{IgG}$ as the secondary antibody (Zymed, USA) (1:10,000 dilution) were used in the detection procedure. The membrane was blocked with $5 \%(\mathrm{w} / \mathrm{v})$ non-fat dried milk in 1 X PBS-T buffer $(137 \mathrm{mM} \mathrm{NaCl}, 2.7 \mathrm{mM}$ $\mathrm{KCl}, 10 \mathrm{mM} \mathrm{Na}_{2} \mathrm{HPO}_{4}, 2 \mathrm{mM} \mathrm{KH}_{2} \mathrm{PO}_{4}$ and 0.05 $\% \quad(\mathrm{v} / \mathrm{v})$ Tween-20) together with primary antibody for $2 \mathrm{~h}$ at room temperature. Then, the membrane was washed three times with PBS-T buffer and incubated with secondary antibody for $1.5 \mathrm{~h}$ at room temperature. After washing three times in PBS-T buffer, the membrane blotted with GFP protein was incubated with 3 $\mathrm{ml}$ of 3,3',5,5'-Tetramethylbenzidine (TMB) substrate until development of signal at desired level. Image was captured using GS800 calibrated imaging Densitometer (BioRad, USA). For membrane blotted with NA1 protein, SuperSignal West Dura Chemiluminescent substrate solution (Pierce, USA) was spread evenly on the membrane for $5 \mathrm{~min}$ and image was captured by CCD camera (Alpha-Innotech Corporation).

\section{RESULTS AND DISCUSSION}

\section{Results}

\section{Construction of pEAQ-HT::NA1 and Its Characterisation}

The full-length $N A 1$ gene of Malaysian strain H5N1 with a molecular size of $1.4 \mathrm{kbp}$ was isolated by PCR and its sequence was confirmed by nucleotide sequencing. The NA1 gene was inserted successfully into $\mathrm{pEAQ}-H T$ vector via $A g e \mathrm{I}$ and SmaI sites with His-tag at C-terminal. Following the gene cloning, the recombinant vector, pEAQ-HT::NA1 was successfully characterized and identified by PCR and RE digestion. The RE profile of different enzymatic digestion verifying the desired pEAQ-HT::NA1 is shown in Figure 2. AgeI produced the linearized pEAQ-HT::NA1 ( 12 kbp) and NA1 gene with His-tag was cleaved out from the pEAQ-HT vector when digested with $A g e \mathrm{I}$ and XhoI. The fragments obtained were approximately $1.4 \mathrm{kbp}$ and $10 \mathrm{kbp}$ in molecular sizes as expected for NA1 gene and pEAQ-HT vector, respectively. Following cloning process, nucleotide sequencing analysis showed an inframe fusion of the NA1 gene with His-tag of pEAQ-HT vector.

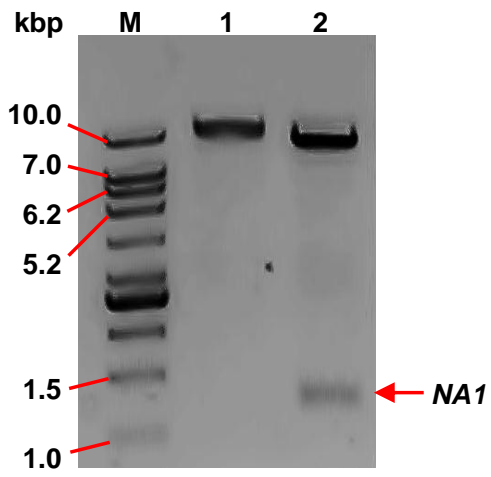

Figure 2. Restriction profile of recombinant pEAQ$H T:: N A 1$. Lane $M$ Vivantis $1 \mathrm{~kb}$ ladder; lane 1 AgeI-digested; lane 2 AgeI- and XhoI-digested. Approximately $1.4 \mathrm{kbp}$ of $N A 1$ fragment is observed after $A g e \mathrm{I}$ and $\mathrm{X} h o \mathrm{I}$ digestion.

\section{Physical Observation of Plants Post- agroinfiltration}

When infiltration was conducted with low OD600 (0.3-0.4) of A. tumefaciens, at 6 Dpi, 
mock-infiltrated (Figure 3a) and Ag/pEAQ-HTGFP-infiltrated (Figure 3c) plant leaves showed minimum symptoms, while the $\mathrm{Ag} / \mathrm{pEAQ}$ $H T:: N A 1-$ infiltrated zones bleached (Figure 3b).

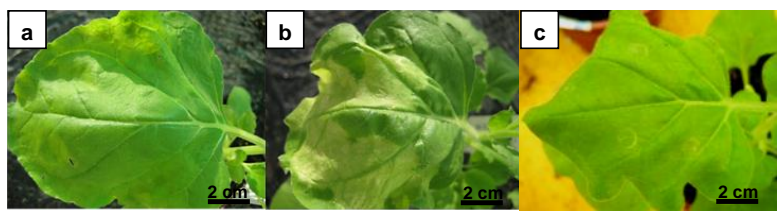

Figure 3. Physical appearances of agroinfiltrated zone with $\mathrm{OD}_{600}$ 0.3-0.4 of $A$. tumefaciens culture after 6 Dpi on (a) mock-infiltrated, (b) pEAQ-HT::NAinfiltrated and (c) pEAQ-HT-GFP-infiltrated tobacco leaves.

\section{Protein Expression Profile of GFP in N. benthamiana}

Following a kinetic expression assessment of pEAQ-HT-GFP on $N$. benthamiana leaves at protein level, specific and distinct GFP protein bands $(\sim 27 \mathrm{kDa})$ were detected in soluble fraction of proteins at 3, 6, 9, 12 Dpi from Ag/pEAQ-HT-GFP-infiltrated leaves using primary rabbit polyclonal anti-GFP antibody (Figure 4). The expression reached the maximal level within 6 to $9 \mathrm{Dpi}$ and diminished slowly from day 12. No band was detected for mockinfiltrated protein samples.

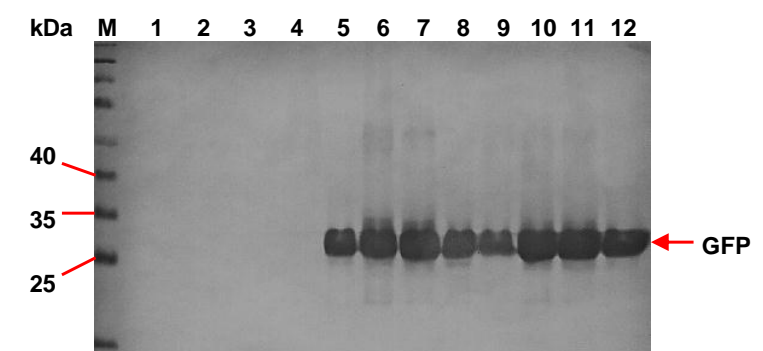

Figure 4. Immunoblot profile of GFP protein isolated from $N$. benthamiana leaves infiltrated with Ag/pEAQ-HT-GFP. Lane $M$ Fermentas PageRuler ${ }^{\mathrm{TM}}$ prestained protein ladder; lanes 1-4 mock-infiltrated control (3, 6, 9, 12 Dpi); lanes 5 \&o 9 infiltrated with Ag/pEAQ-HT-GFP at 3 Dpi; lanes 6 \& 10 infiltrated with $\mathrm{Ag} / \mathrm{pEAQ}$ $H T$-GFP at $6 \mathrm{Dpi}$; lanes $7 \& 11$ infiltrated with $\mathrm{Ag} / \mathrm{pEAQ}-H T-G F P$ at $9 \mathrm{Dpi}$; lanes 8 \& 12 infiltrated with $\mathrm{Ag} / \mathrm{pEAQ}-H T$-GFP at $12 \mathrm{Dpi}$. Approximately $27 \mathrm{kDa}$ of GFP band is observed in leaves infiltrated with $\mathrm{Ag} / \mathrm{pEAQ}-H T$-GFP only at 3, 6, 9, 12 Dpi.

\section{Expression of NA1 Gene in N. \\ benthamiana at RNA and Protein Levels}

The intact total RNA of infiltrated tobacco leaves was successfully extracted and subjected to RT-PCR amplification. Using the specific primers (NeuF-AgeI and NeuR-SmaI), a specific and district band $(\sim 1.4 \mathrm{kbp})$ of the full-length
NA1 was successfully amplified from cDNA sample of Ag/pEAQ-HT::NA1-infiltrated plant on 6 Dpi as shown in Figure 5 (Lane 2). In contrast, no amplification was obtained from cDNA sample of mock-infiltrated plant (Figure 5, Lane 1) and RNA sample of $A g / p E A Q-$ $H T:$ NA1-infiltrated plant (Figure 5, Lane 3).

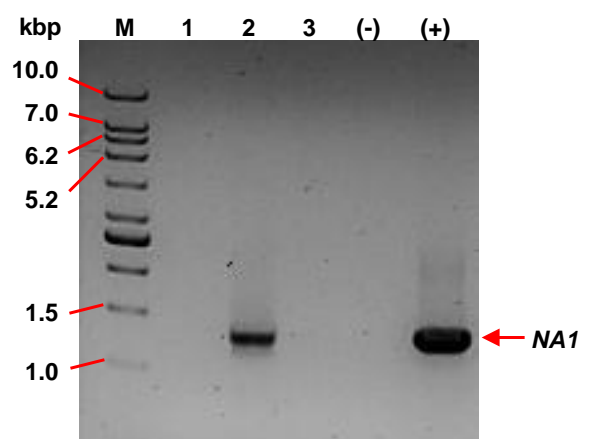

Figure 5. RT-PCR amplification profile of RNA extracted from the tobacco leaves infiltrated with Ag/pEAQ-HT::NA1. Lane $M$ Vivantis $1 \mathrm{~kb}$ ladder; lane $1 \mathrm{cDNA}$ of mock-infiltrated leaf; lane 2 cDNA of $\mathrm{Ag} / \mathrm{pEAQ}-H T:: N A 1$-infiltrated leaf; lane 3 RNA of Ag/pEAQ-HT::NA1-infiltrated leaf; lane (-) PCR non-template control; lane (+) PCR positive control. Approximately $1.4 \mathrm{kbp}$ of NA1 amplicon similar to PCR positive control is observed in Ag/pEAQ-HT::NA1-infiltrated leaf only.

Using the protein extraction method as described above, the insoluble fraction of protein containing the NA1 protein was recognized by polyclonal anti-NA antibody in Western blotting analysis. In contrast, negative outcome was obtained from the detection of recombinant NA1 protein in soluble fraction. The insoluble NA1 protein band with a molecular size of $\sim 56$ $\mathrm{kDa}$ was detected in a sample of $\mathrm{Ag} / \mathrm{pEAQ}$ $H T:$ NA1-infiltrated plant (Figure 6, Lane 2) but not in that of mock-infiltrated plant (Figure 6, Lane 1). Ni-charged IMAC resin purification was done on the crude protein extracted and similar band size was detected (Figure 6, Lane 4) with unspecific background reduced to minimum.

\section{Discussion}

The present study was aimed at developing a recombinant vaccine candidate, NA1, for the Malaysian isolate of AI virus strain $\mathrm{H} 5 \mathrm{~N} 1$ in a plant system, tobacco. This was commenced by inserting the $N A 1$ gene into CPMV-based plant expression vector, pEAQ-HT, to obtain recombinant pEAQ-HT::NA1. The expression profile of NA1 protein in this particular expression system was firstly determined by using a reporter, GFP. Based on the period attaining the most optimal expression level of 
GFP, the NA1 expression in tobacco was then studied at both RNA and protein levels.

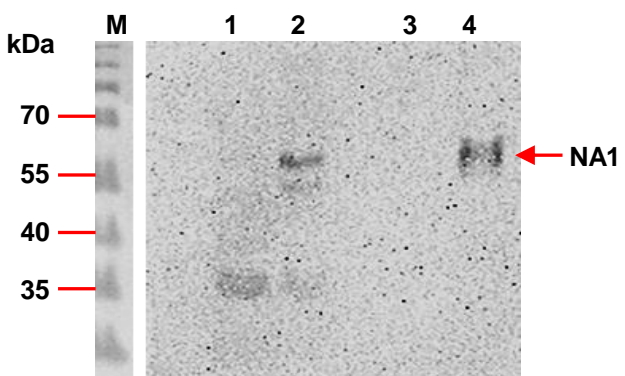

Figure 6. Immunoblot profile of NA1 protein isolated from $N$. benthamiana leaves infiltrated with Ag/pEAQ-HT::NA1 at 6 Dpi. Lane $M$ Fermentas PageRuler ${ }^{\mathrm{TM}}$ prestained protein ladder; lane 1 mock-infiltrated control (insoluble fraction of protein); lane 2 infiltrated with $\mathrm{Ag} / \mathrm{pEAQ}-H T:: \mathrm{NA} 1$ (insoluble fraction of protein); lane 3 mock-infiltrated control (IMAC resin purified); lane 4 infiltrated with $\mathrm{Ag} / \mathrm{pEAQ}-$ $H T::$ NA1 (IMAC resin purified). Approximately $56 \mathrm{kDa}$ of NA1 band is observed in insoluble protein fraction of leaves infiltrated with Ag/pEAQ-HT::NA1 before and after IMAC resin purification.

In the present study, a relatively low OD600 $(0.3-0.4)$ was used for the delivery of recombinant vectors. This was considered necessary given the hypersensitive response of plant leaves to $A$. tumefaciens infection as reported $[9,10]$. This is in agreement with several reports in which A. tumefaciens OD600 used ranged from 0.2 to $0.5[11,12,13]$. There are reports, however, which have clearly showed the use of higher $A$. tumefaciens density with OD600 range of 1.0-1.2 for plant infiltration $[14,15,16]$. The effects of $A$. tumefaciens density have in fact been well-studied for stable Agrobacterium-mediated transformation system in term of expression efficiency and plant tissues hypersensitivity response $[9,17]$, but not the detail mechanism. For agroinfiltration transient approach, $A$. tumefaciens density has been reported as an independent factor for GFP expression [18]. N. tabacum responses to this plant pathogen had been studied [10] and three of the major responses recorded from the infiltrated zones were the induction of pathogenesis-related gene expression, chlorosis and inhibition of leaf expansion. In addition, Gils and friends [19] also suggested that plant leaves responded differently to different constructs targeting their recombinant proteins in different cell compartments.

Based on the expression profile of GFP, protein expression levels at 6 and 9 Dpi were comparable. Hence, we decided to harvest and analyse the infiltrated plants at 6 Dpi for NA1 expression. This expression profile was in agreement with the previous research $[13,18$, 20]. Sheludko and colleagues [20] found that GFP accumulation achieved the maximal level at 3 Dpi and remained stable up to 8 Dpi. Similar tendency was mentioned by another report, which explained that within 4-5 Dpi, the intensity of GUS staining reached the peak level and decreased gradually after that time [13]. Phenomenon of the decreasing expression level can be explained by triggering of RNA silencing mechanism which stops the foreign gene expression [21, 22].

The overall results of RT-PCR and Western blotting analyses confirmed the successful transcription and translation of NA1 gene in infiltrated leaf sample. In order to eliminate the possibility of plasmid DNA contamination during extraction, RNA sample without RT step had been recruited in PCR amplification procedure. Based on the results obtained, the generation of NA1 mRNA in infiltrated leaf sample was proven and the production of NA1 protein was expected. Following the detection of $\sim 56 \mathrm{kDa}$ protein from Ag/pEAQ-HT::NA1infiltrated leaves, but not in that of mockinfiltrated leaves, we herewith claimed that the plant-based full-length NA1 protein had been produced successfully in $N$. benthamiana. This indicates the native $N A 1$ gene without sequence modification can be expressed in tobacco leaves using CPMV system, but unlikely in the insoluble state. The expected size of full-length native NA1 (450 amino acids) is $\sim 49 \mathrm{kDa}$, and thus the observed band of $\sim 56 \mathrm{kDa}$ protein signified a glycosylated NA1. Similar size of recombinant NA was obtained by Schmidt and colleagues [23] who used baculovirus system. In their study, with the use of mass spectrometry, MALDI-ToF, they estimated the molecular weight of the recombinant NA protein fragments to be 54.6 $\mathrm{kDa}$ and $58.5 \mathrm{kDa}$. On the other hand, Yongkiettrakul and colleagues [24] reported that, in yeast system, the predominant hyperglycosylated recombinant NA has a size of $\sim 72 \mathrm{kDa}$ with $\sim 60 \mathrm{kDa}$ protein as an intermediate product of glycosylation.

In Western blotting analysis, unspecific background generated from insoluble fraction of protein is most likely due to the low stringent immunogenicity of polyclonal antibody which corresponds only to 15 amino acids at the Cterminal of NA. To minimise this predicament, the cloning method of $N A 1$ gene into pEAQ$H T$ vector has allowed the generation of Cterminal His-tag to facilitate the purification of recombinant proteins by $\mathrm{Ni}$-charged IMAC resin. 
This purification step of the total insoluble protein had increased the specificity of detection by which the similar band size of $\sim 56 \mathrm{kDa}$ (Figure 6, Lane 4) was resulted with unspecific background reduced to minimum. IMAC is a widely used purification technique for recombinant His-tagged proteins. IMAC resin comprises of iminodiacetic acid charged with transition metals such as $\mathrm{Cu}^{2+}, \mathrm{Ni}^{2+}, \mathrm{Co}^{2+}$ or $\mathrm{Zn}^{2+}$ and offers a high selectivity of binding to His-tagged proteins [25]. Mohanty and Miener [26] reported His-tag length plays a significant role in relation to protein yield, but its insertion position does not. However, for native protein with signal sequence, in general, His-tag in $\mathrm{N}$ terminal is impractical as it will be cleaved off after transporting the protein to its targeted location. A few related studies have revealed its feasibility in purifying recombinant proteins [27, 28 ] which can be further employed in subsequent investigations such as immunogenicity assessment. Nevertheless, this purification step in this case has further enhanced the identity of plant-made NA1 protein.

Expression of influenza NA has been well studied in mammalian cell [29], yeast [24] and baculovirus systems [4, 5, 23]. In plant, different types of AI NA were expressed in $N$. benthamiana, i.e. NA type 2 from influenza A/Wyoming/3/03 (H3N2) [30], NA1 from influenza A/Hatay/2004 (H5N1) [31] and A/Vietnam/04 (H5N1), reported as personal communication in a review article by Musiychuk et al. [32]. These three studies reported the expression of soluble form of recombinant NA protein. In the present study we obtained insoluble recombinant NA1, apparently contradicting these reports. The $N A 1$ sequence that we used was native, not optimised based on plant codon usage. The differences in synonymous codon usage between heterologous expression system and the natural host were believed to be significant. Codon-usage variations among different species are frequently related to the failures in heterologous recombinant protein expression, such as lack of expression and truncated or non-functional proteins production [33]. However, in present study, insolubility of recombinant protein was discovered from native sequence expression, which is seldom reported in plant system. Improper folding and protein insolubility could be due to biased codon usage as translational pause occurs in the presence of slow codons [34].

Many studies have shown that optimisation or harmonisation of codon usage according to expression host increased protein yield considerably $[35,36,37,38]$. Among these, report by Angov's group [35] was the most impressive as the expression of sequence harmonised genes exceeded that of native genes by 4 - to 100-folds. Another potential protective surface glycoprotein of AI virus, HA, has also been well investigated in heterologous expression studies. HA type 3 and 5 were expressed successfully in tobacco either by transient [28, $30,39,40,41]$ or stable [41] transformations. Most of the studies reported gene sequence optimisation before subjection to heterologous expression in plant system. The antigenicity of these plant-produced HAs has been confirmed in animal models [28, 39, 40]. Apparently, gene sequence optimisation is crucial for expressing foreign genes in plant system.

However, codon optimisation is not always obligatory for some cases. There are a few exceptional cases in which codon optimisation based on host system does not necessarily give positive effect on expression level. Generally, a higher codon adaptation index (CAI) is generated by codon optimised sequence and protein expression level is believed to be high. However, the $\mathrm{A}+\mathrm{T}$ content are consequently increases with the increase of CAI for a foreign gene. This might contribute to the instability of mRNA and hence reduces protein expression level [42, 43]. This is supported by LaguíaBecher et al. [44], who demonstrated that the higher the $\mathrm{A}+\mathrm{T}$ content in codon optimised gene, the lower the expression obtained. The effect of codon optimisation on Toxoplasma gondii surface antigen 1 ( $S A G 1)$ gene was studied in tobacco system. $S A G 1$ sequence was optimised based on plant codon usage, CAI value and the $\mathrm{A}+\mathrm{T}$ content were both increased in this case. Results showed that the protein expression level was significantly lowered for optimised variant as compared to native gene. However, advance studies should be carried out in order to comprehend further. Besides, Maclean and colleagues [15] found that human codonoptimised human papillomavirus type 16 (HPV16) L1 gene resulted to the highest accumulation of the protein in tobacco system as compared to plant codon-optimised and native sequences. In this report, they demonstrated that the plant codon-optimised sequence did not generate detectable protein while native sequence caused the second highest accumulation of the L1 protein. In this case, the $\mathrm{A}+\mathrm{T}$ content cannot be responsible as native sequence was holding a higher value. The reason behind the poor expression of plant codon-optimised gene 
remains unknown and requires further investigations.

Therefore, the native sequence of $N A 1$ was applied in present study instead of codon optimised gene, as its outcome was thought to be unpredictable and worthwhile to be studied. The findings of the present study are the first of its kind to report the insoluble state of expression of a native NA1 sequence in tobacco system. Nonetheless, further modification on the insoluble NA1 is absolutely necessary in order to make the downstream assays such as protein activity and immunogenicity possible. For instance, there are various in vitro refolding processes reported to be effective in renaturing the insoluble recombinant proteins into bioactive form $[45,46]$. This is commonly done for E. coli recombinant proteins as this system tends to produce recombinant proteins as inclusion body.

\section{CONCLUSION}

In conclusion, the native $N A 1$ sequence has been successfully expressed in an insoluble form in tobacco. This study might also signify the necessity of the use of optimised sequences for expression work. Further investigations, like protein characterisations and codon optimisation need to be conducted in order to make a comparison with the present study and produce NA1 protein that is suitable for subsequent immunogenicity trial. Nevertheless, this study provides a great opportunity for the exploration of plant-manufactured NA1 protein as vaccine candidate. In future, other palatable plant species like alfalfa or lettuce could serve as a target system as combined feed/vaccine for poultry to combat AI disease.

\section{ACKNOWLEDGMENTS}

We thank Professor George Lomonossoff and Dr Paolo Lenzi (John Innes Centre, Norwich, UK) for supplying the plant viral vector, facilities and invaluable technical supports. This study is financially supported by Ministry of Agriculture and Agro-Based Industries (MOA), Malaysia.

\section{REFERENCES}

1. Kilbourne ED, Johansson BE, Grajower B (1990) Independent and disparate evolution in nature of influenza A virus hemagglutinin and neuraminidase. Proc Natl Acad Sci USA. 87: 786790.
2. Monto AS (2006) Vaccines and antiviral drugs in pandemic preparedness. Emerging Infect Dis. 12: 55-61.

3. Okomo-Adhiambo M, Nguyen HT. Sleeman K, Sheu TG, Deyde VM, Garten RJ, Xu X, Shaw MW, Kilmov AI, Gubareva LV (2010) Host cell selection of influenza neuraminidase variants: Implications for drug resistance monitoring in A (H1N1) viruses. Antiviral Res. 85: 381-388.

4. Brett IC, Johansson BE (2005) Immunization against influenza A virus: Comparison of conventional inactivated, live-attenuated and recombinant baculovirus produced purified hemagglutinin and neuraminidase vaccines in a murine model system. Virology. 339: 273-280.

5. Johansson BE, Brett IC (2008) Recombinant influenza $B$ virus $\mathrm{HA}$ and NA antigens administered in equivalent amounts are immunogenically equivalent and induce equivalent homotypic and broader heterovariant protection in mice than conventional and live influenza vaccines. Hum Vaccines. 4: 420-424.

6. Ning T, Xie T, Qiu Q, Yang W, Zhou S, Zhou L, Zheng C, Zhu Y, Yang D (2008) Oral administration of recombinant human granulocyte-macrophage colony stimulating factor expressed in rice endosperm can increase leukocytes in mice. Biotechnol Lett. 30: 16791686.

7. Tacket CO, Pasetti MF, Edelman R, Howard JA, Streatfield S (2004) Immunogenecity of recombinant LT-B delivered orally to humans in transgenic corn. Vaccine. 22: 4385-4389.

8. Sainsbury F, Liu L, Lomonossoff GP (2009a) Cowpea Mosaic Virus-based systems for the expression of antigens and antibodies in plants. In: Faye L, Gomord V, Eds. Methods in Molecular biology, Recombinant Proteins from Plants. New York: Humana Press. 25-39.

9. Kuta DD, Tripathi L (2005) Agrobacteriuminduced hypersensitive necrotic reaction in plant cells: a resistance response against Agrobacteriummediated DNA transfer. Afr J Biotechnol. 4: 752757.

10. Pruss GJ, Nester EW, Vance V (2008) Infiltration with Agrobacterium tumefaciens induces host defense and development-dependent responses in the infiltrated zone. Mol PlantMicrobe Interact. 21: 1528-1538.

11. Alamillo JM, Monger W, Sola I, Garcia B, Perrin Y, Bestagno M, Burrone OR, Sabella P, PlanaDuran J, Enjuanes L, Lomonossoff GP, Garcia JA (2006) Use of virus vectors for the expression in plants of active full-length and single chain anti-coronavirus antibodies. Biotechnol J. 1: 1103-1111.

12. Komarova TV, Skulachev MV, Zvereva AS, Schwarts AM, Dorokhov YL, Atabekov JG (2006) New viral vector for efficient production of target proteins in plants. Biochemistry (Moscow). 71: 846-850. 
13. Wroblewski T, Tomczak A, Michelmore R (2005) Optimization of Agrobacterium-mediated transient assays of gene expression in lettuce, tomato and Arabidopsis. Plant Biotechnol J. 3: 259-273.

14. Lindbo JA (2007) TRBO: A high-efficiency Tobacco Mosaic Virus RNA-Based Overexpression Vector. Plant Physiol. 145: 12321240.

15. Maclean J, Koekemoer M, Olivier AJ, Stewart D, Hitzeroth II, Rademacher T, Fischer R, Williamson AL, Rybicki EP (2007) Optimization of human papillomavirus type 16 (HPV-16) L1 expression in plants: comparison of the suitability of different HPV-16 L1 gene variants and different cell-compartment localization. J Gen Virol. 88: 1460-1469.

16. Sainsbury F, Thuenemann EC, Lomonossoff GP (2009b) pEAQ: versatile expression vectors for easy and quick transient expression of heterologous proteins in plants. Plant Biotechnol J. 7: 1-12.

17. Hasnat R, Abbasi NA, Hafiz IA, Ahmad T, Chudhary Z (2008) Effect of different bacterial dilutions on transformation efficiency of hot chilli (Capsicum frutescens L.) varieties. Pak J Bot. 40(6): 2655-2662.

18. Wydro M, Kozubek E, Lehmann P (2006) Optimization of transient Agrobacterium-mediated gene expression system in leaves of Nicotiana benthamiana. Acta Biochim Pol. 53: 289-298.

19. Gils M, Kandzia R, Marillonnet S, Klimyuk V, Gleba Y (2005) High-yield production of authentic human growth hormone using a plant virus-based expression system. Plant Biotechnol J. 3: 613-620.

20. Sheludko YV, Sindarovska YR, Gerasymenko IM, Bannikova MA, Kuchuk NV (2007) Comparison of several Nicotiana species as hosts for high-scale Agrobacterium-mediated transient expression. Biotechnol Bioeng. 96: 608-614.

21. Johansen LK, Carrington JC (2001) Silencing on the spot. Induction and suppression of RNA silencing in the Agrobacterium-mediated transient expression system. Plant Physiol. 126: 930-938.

22. Voinnet O, Rivas S, Mestre P, Baulcombe D (2003) An enhanced transient expression system in plants based on suppression of gene silencing by the p19 protein of tomato bushy stunt virus. Plant J. 33: 949-956.

23. Schmidt PM, Attwood RM, Mohr PG, Barrett SA, McKimm-Breschkin JL (2011) A generic system for the expression and purification of soluble and stable influenza Neuraminidase. PLoS ONE. 6(2):e16284. DOI: 10.1371/journal.pone.0016284.

24. Yongkiettrakul S, Boonyapakron K, Jongkaewwattana A, Wanitchang A, Leartsakulpanich U, Chitnumsub P, Eurwilaichitr L, Yuthavong Y (2009) Avian influenza A/H5N1 neuraminidase expressed in yeast with a functional head domain. J Virol Methods. 156: 44-51.
25. Porath J, Carlsson J, Olsson I, Belfrage G (1979) Metal chelate affinity chromatography, a new approach to protein fractionation. Nature. 258: 598-599.

26. Mohanty AR, Wiener MC (2004) Membrane protein expression and production: effects of polyhistidine tag length and position. Protein Expres Purif. 33: 311-325.

27. Magnusdottir A, Johansson I, Dahlgren LG, Nordlund P, Berglund H (2009) Enabling IMAC purification of low abundance recombinant proteins from E. coli lysates. Nat Methods. 6: 477-478.

28. Shoji Y, Farrance CE, Bi H, Shamloul M, Green B, Manceva S, Rhee A, Ugulava N, Roy G, Musiychuk K, Chichester JA, Mett V, Yusibov V (2009) Immunogenicity of hemagglutinin from A/Bar-headed Goose/Qinghai/1A/05 and A/Anhui/1/05 strains of H5N1 influenza viruses produced in Nicotiana benthamiana plants. Vaccine. 27: 3467-3470.

29. Tanimoto T, Nishimura Y, Matsuura Y, Fuke I, Ishikawa T, Yamanishi K, Tamura S (2004) Expression of influenza neuraminidase in $\mathrm{CHO}-$ K1 cells. Int Congr Ser. 1263: 568-572.

30. Mett V, Musiychuk K, Bi H, Farrance CE, Horsey A, Ugulava N, Shoji Y, de la Rosa P, Palmer GA, Rabindran S, Streatfield SJ, Boyers A, Russell M, Mann A, Lambkin R, Oxford JS, Schild GC, Yusibov V (2008). A plant-produced influenza subunit vaccine protects ferrets against virus challenge. Influenza Other Respir Viruses. 2: 33-40.

31. Phan HT, Conrad U (2011) Membrane-based inverse transition cycling: an improved means for purifying plant-derived recombinant proteinelastin-like polypeptide fusions. Int J Mol Sci. 12: 2808-2821.

32. Musiychuk K, Stephenson N, Bi H, Farrance CE, Orozovic G, Brodelius M, Brodelius P, Horsey A, Ugulava N, Shamloul A, Mett V, Rabindran S, Streatfield SJ, Yusibov V (2007) A launch vector for the production of vaccine antigens in plants. Influenza. 1: 19-25.

33. Kurland C, Gallantt J (1996) Errors of heterologous protein expression. Curr Opin Biotechnol. 7: 489-493.

34. Thanaraj TA, Argos P (1996) Ribosome-mediated translational pause and protein domain organization. Protein Sci. 5: 1594-1612.

35. Angov E, Hillier CJ, Kincaid RL, Lyon JA (2008) Heterologous protein expression is enhanced by harmonizing the codon usage frequencies of the target gene with those of the expression host. PLoS ONE. 3(5):e2189. DOI: 10.1371/journal.pone.0002189.

36. Chang SW, Lee GC, Shaw JF (2006) Codon optimization of Candida rugosa lip1 gene for improving expression in Pichia pastoris and biochemical characterization of the purified recombinant LIP1 lipase. J Agric Food Chem. 54: 815-822. 
37. Geyer BC, Fletcher SP, Griffin TA, Lopker MJ, Soreq H, Mor TS (2007) Translational control of recombinant human acetylcholinesterase accumulation in plants. BMC Biotechnol. 7: 2741.

38. Suo G, Chen B, Zhang J, Duan Z, He Z, Yao W, Yue C, Dai J (2006) Effect of codon modification on human BMP2 gene expression in tobacco plants. Plant Cell Rep. 25: 689-697.

39. D'Aoust MA, Lavoie PO, Couture MM-J, Trépanier S, Guay JM, Dargis M, Mongrand S, Landry N, Ward BJ, Vézina LP (2008) Influenza virus-like particles produced by transient expression in Nicotiana benthamiana induce a protective immune response against a lethal virus challenge in mice. Plant Biotechnol J. 6: 930-940.

40. Shoji Y, Chichester JA, Bi H, Musiychuk K, de la Rosa P, Goldschmidt L, Horsey A, Ugulava N, Palmer GA, Mett V, Yusibov V (2008) Plantexpressed HA as a seasonal influenza vaccine candidate. Vaccine. 26: 2930-2934.

41. Spitsin S, Andrianov V, Pogrebnyak N, Smirnov Y, Borisjuk N, Portocarrero C, Veguilla V, Koprowski H, Golovkin M (2009) Immunological assessment of plant derived avian flu H5/HA1 variants. Vaccine. 27: 1289-1292.

42. De Rocher EJ, Vargo-Gogola TC, Diehn SH, Green PJ (1998) Direct Evidence for Rapid Degradation of Bacillus thuringiensis Toxin mRNA as a Cause of Poor Expression in Plants. Plant Physiol. 117: 1445-1461.

43. Hollams EM, Giles KM, Thomson AM, Leedman PJ (2002) mRNA Stability and the Control of Gene Expression: Implications for Human Disease. Neurochem Res. 27: 957-980.

44. Laguía-Becher M, Martín V, Kraemer M, Corigliano M, Yacono ML, Goldman A (2010) Clemente M. Effect of codon optimization and subcellular targeting on Toxoplama gondii antigen SAG1 expression in tobacco leaves to use in subcutaneous and oral immunization in mice. BMC Biotechnol. 10: 52-66.

45. Heiker JT, Klöting N, Blüher M, Beck-Sickinger AG (2010) Access to gram scale amounts of functional globular adiponectin from E. coli inclusion bodies by alkaline-shock solubilization. Biochem Biophys Res Commun. 398: 32-37.

46. Richter W, Hermsdorf T, Kronbach T, Dettmer D (2002) Refolding and purification of recombinant human PDE7A expressed in Escherichia coli as inclusion bodies. Protein Expres Purif. 25: 138-148. 